\title{
Prevalence of class 1 integron in Escherichia coli isolated from animal sources in Iran: a systematic review and meta-analysis
}

\author{
Maryam Karimi Dehkordi ${ }^{*}$, Mehrdad Halaji ${ }^{2}$ and Samereh Nouri ${ }^{3}$
}

\begin{abstract}
Background: Among the genetic elements, integrons may contribute to the widespread incidence and spreading of antibiotic resistance among Escherichia coli isolates. Accordingly, this review aims to investigate the prevalence of class 1 integron in E. coli isolated from animal sources in Iran.

Methods: This systematic literature search was performed from January 1, 2000 to the end of May 1, 2019. Then, publications that met our inclusion criteria were selected for data extraction and analysis. Also, the quality of included studies was independently assessed by two researchers based on the Joanna Briggs Institute. Metaanalysis was performed by the Comprehensive Meta-Analysis (CMA) software using the random effects model, Cochran's $Q$, and $P$ tests. Publication bias was estimated by funnel plot and Egger's linear regression test.

Results: Based on inclusion criteria, five studies were included to meta-analysis. From those studies, the pooled prevalence of integrons was $33 \%(95 \% \mathrm{Cl}, 23.8-43.7 \%)$ ranging from 23.8 to $52.4 \%$. There was a significant heterogeneity among the 5 studies $\left(x^{2}=11.73 ; p<0.019 ; P^{2}=65.91 \%\right)$. Additionally, Begg's and Egger's tests were performed to quantitatively evaluate the publication biases. According to the results of Begg's test $(z=1.22, p=$ 0.22 ) and Egger's test ( $t=3.03, p=0.056)$, a significant publication bias was not observed.

Conclusions: Our finding revealed the relatively high prevalence of class 1 integrons among E. coli isolates. Moreover, there was a significant heterogeneity among studies and subgroup analysis also showed that there was no difference about prevalence of class 1 integrons among different sample source.
\end{abstract}

Keywords: Escherichia coli, Antibiotic resistance, Integron, Meta-analysis, Animal source

\section{Background}

Enterobacteriaceae is a diverse group of Gram-Negative Bacteria (GNB) causing various diseases in humans and animals. In this family, Escherichia coli (E. coli) is the most common commensal bacteria in the gastrointestinal tract microflora of both humans and animals [1,2]. As carriers of the bacteria, E. coli can be found in animals such as cattle, sheep, pigs, deer, dogs, and poultry [3]. Infected animals can shed the bacteria in their feces and easily contaminate their environment. People in contact with infected animals and their

\footnotetext{
* Correspondence: ma.karimivet58@gmail.com

${ }^{1}$ Department of Clinical Sciences, Faculty of Veterinary Medicine, Shahrekord Branch, Islamic Azad University, Shahrekord, Iran

Full list of author information is available at the end of the article
}

environment are exposed to these bacteria [4]. Antibiotics are commonly used for prophylaxis and treatment of infected humans and animals. Inadequate selection and abuse of antibiotics may lead to resistance in various bacteria and make the treatment of bacterial infections more difficult $[5$, 6]. Multidrug-resistant (MDR) in GNB, especially in E. coli, has become one of the major challenges to human and animal health $[5,7]$. Intrinsic and acquired resistance mechanisms are the cause of antimicrobial resistance (AMR) among E. coli. E. coli strains have a considerable capacity to acquire resistance genes mostly through horizontal gene transfer. Horizontal gene transfer is an important mechanism for the rapid spread of antibiotic resistance genes between GNB species $[8,9]$.

(c) The Author(s). 2020 Open Access This article is licensed under a Creative Commons Attribution 4.0 International License, which permits use, sharing, adaptation, distribution and reproduction in any medium or format, as long as you give appropriate credit to the original author(s) and the source, provide a link to the Creative Commons licence, and indicate if changes were made. The images or other third party material in this article are included in the article's Creative Commons licence, unless indicated otherwise in a credit line to the material. If material is not included in the article's Creative Commons licence and your intended use is not permitted by statutory regulation or exceeds the permitted use, you will need to obtain permission directly from the copyright holder. To view a copy of this licence, visit http://creativecommons.org/licenses/by/4.0/. 


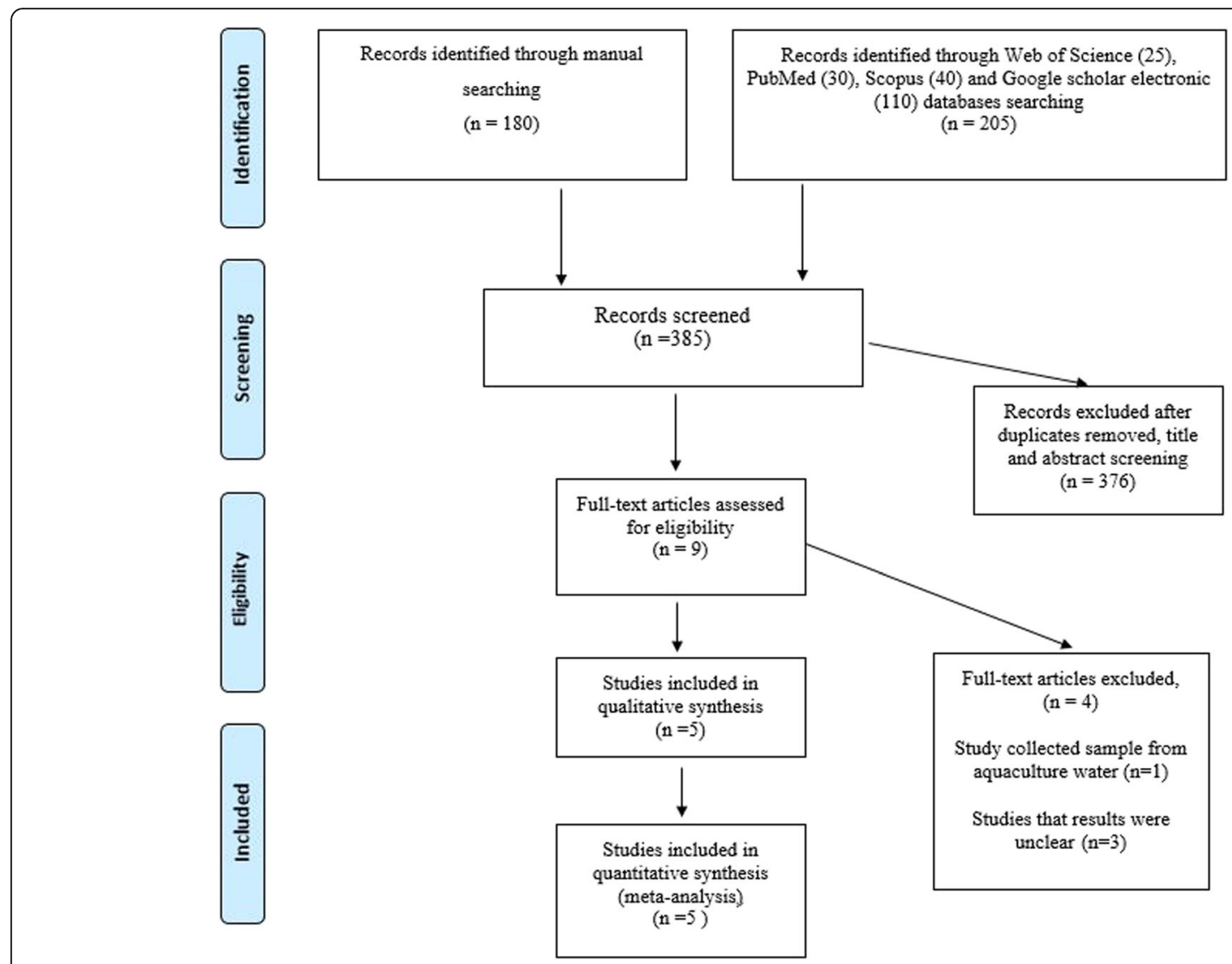

Fig. 1 Flow chart of study selection for inclusion in the systematic review

In recent years, different acquired resistance mechanisms, including bacteriophages, transposons, plasmids, and integrons, have been identified involving the spread of resistance genes in the bacteria [10]. Among the genetic elements, integrons may also contribute to the widespread incidence and spread of antibiotic resistance [11]. These elements are capable of capturing, integrating, and mobilizing antibiotic resistant gene cassettes. The integrons were classified into three important classes, including 1,2 , and 3 , based on the genetic relatedness of the integrase intI gene sequence. Among them, class 1 integrons are more frequent in GNB [12].

Metallo-beta-lactamase (MBL) is commonly encoded on the gene cassettes harboring class 1 integron and circulated simply in bacterial populations [13].
Additionally, newly extended spectrum beta lactamases (ESBL)-encoding genes are usually located on integronlike structures (such as blaCTX-M, blaGES, or blaVEB1) [14]. In this regard, since antibiotics are widely used in animal sources, the presence of integrons and antibiotic resistant gene in animal products has become a widespread concern [15].

Thus, understanding the prevalence of class 1 integrons among animal sources can play a crucial role in controlling and transferring them to humans, which may help to prevent the spread of resistance determinants in GNB. There are significant data gaps regarding class 1 integron from an animal source in Iran. Accordingly, this review aims to investigate the prevalence of class 1 integron in E. coli isolated from animal sources in Iran.

Table 1 Characteristics of studies included in the meta-analysis

\begin{tabular}{|c|c|c|c|c|c|c|c|}
\hline Study & Publication year & City or province & Sample source & Type of animal & Sample size & Int1 & Diagnostic method \\
\hline Taghadosi & 2019 & Kerman & Faecal & Healthy cattles and goats & 18 & 9 & PCR \\
\hline Staji & 2018 & Tehran & Diarrheic & Cattle and poultry farms & 63 & 15 & PCR \\
\hline Kohansal & 2018 & Fasa & Stool samples & Diarrheic calves & 71 & 23 & PCR \\
\hline Kheiri & 2016 & Karaj & Faecal & Healthy chicken, cattle, and sheep & 150 & 36 & PCR \\
\hline Bakhshi & 2014 & Tehran & Diarrheic & Calves & 21 & 11 & PCR \\
\hline
\end{tabular}




$\begin{array}{lccccc} & \text { Total } & \begin{array}{c}\text { Event } \\ \text { rate }\end{array} & \begin{array}{c}\text { Lower } \\ \text { limit }\end{array} & \begin{array}{c}\text { Upper } \\ \text { limit }\end{array} & \begin{array}{c}\text { Relative } \\ \text { weight }\end{array} \\ \text { Taghadosi, 2019 } & 9 / 18 & 0.500 & 0.284 & 0.716 & 13.90 \\ \text { Staji, 2018 } & 15 / 63 & 0.238 & 0.149 & 0.358 & 21.21 \\ \text { Kohansal, 2018 } & 23 / 71 & 0.324 & 0.226 & 0.441 & 23.32 \\ \text { Kheiri, 2016 } & 36 / 150 & 0.240 & 0.178 & 0.315 & 26.47 \\ \text { Bakhshi, 2014 } & 11 / 21 & 0.524 & 0.318 & 0.721 & 15.11 \\ & & 0.330 & 0.238 & 0.437 & \end{array}$

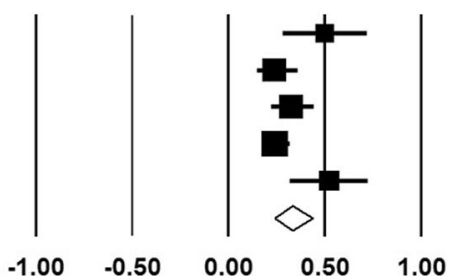

Fig. 2 Forest plot of the meta-analysis of integron in animal sources

\section{Methods}

\section{Search strategies}

The present study was designed according to the Preferred Reporting Items for Systematic Reviews and Meta-Analyses (PRISMA) guidelines (Additional file 1). A systematic literature search was done from January 1, 2000 to the end of May 1, 2019 (using the Web of Science, PubMed, Scopus, and Google Scholar electronic databases) to search for studies published by Iranian authors. The keywords search was carried out using medical subject headings (MeSH) terms such as "Escherichia coli," "E. coli," "Integron," AND "Int1" "antibiotic resistance," "incidence," "distribution," "prevalence," and related terms AND "Iran" individually or combined together in the title or abstract keywords fields.

\section{Selection criteria and quality assessment}

The search was limited to original articles published in English or Persian language with English abstract indexed in the Web of Science, PubMed, Scopus, and Google Scholar databases.
The inclusion criteria was as followed: The crosssectional studies reporting the frequency and prevalence of integron in $E$. coli isolates obtained from animal sources and articles published in English or Persian language with English abstract. In studies that samples were obtained from sources other than animal, and the primary sample size unclear and the review, case reports and letters to the editor's articles were excluded.

Two reviewers determined whether the articles met the inclusion criteria, the titles, abstracts, and full texts of articles independently screened with the related keywords in the databases. Discrepancies among reviewers were resolved by consensus. Furthermore, searching references from included studies/reviews as manual search was performed.

\section{Quality assessment and data extraction}

The quality of included studies was independently assessed by two researchers based on the Joanna Briggs Institute and any disagreements were resolved by consensus.

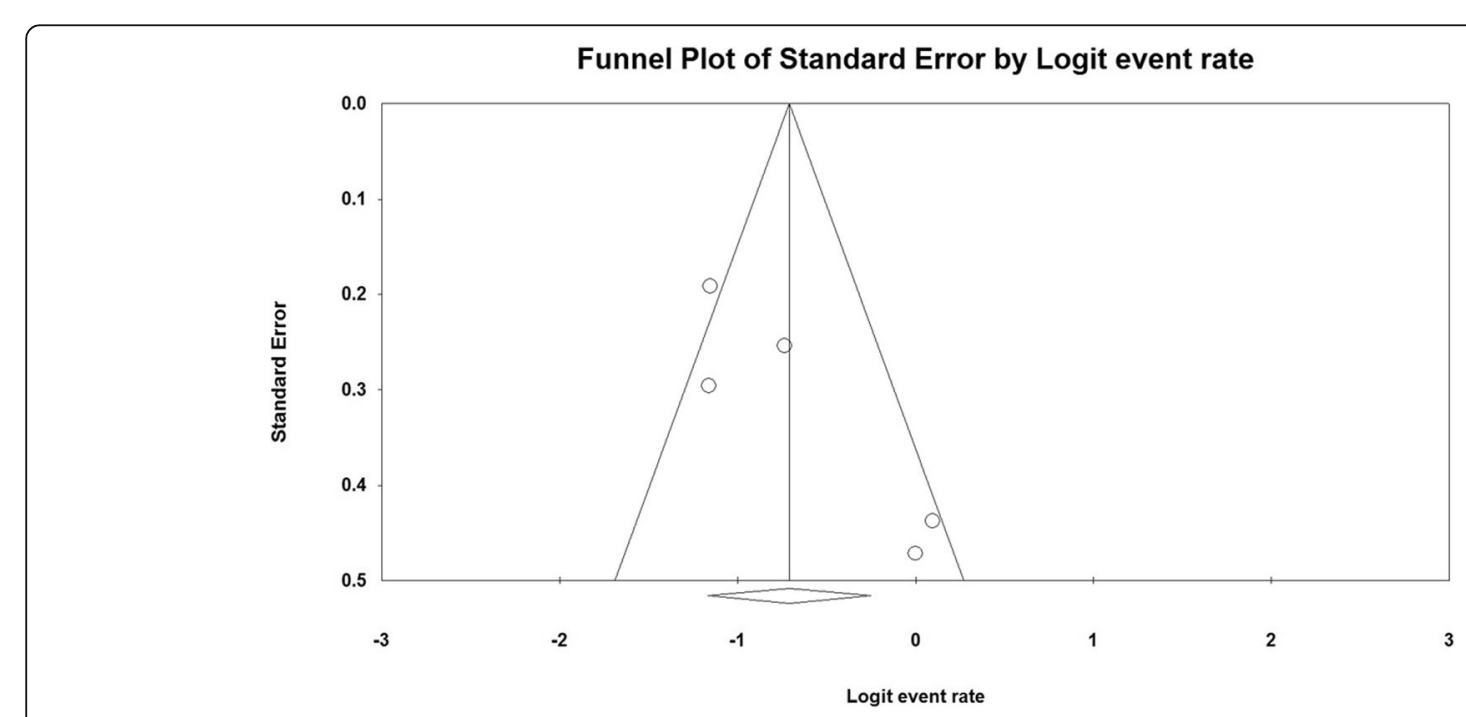

Fig. 3 Funnel plot of publication bias for the included studies 


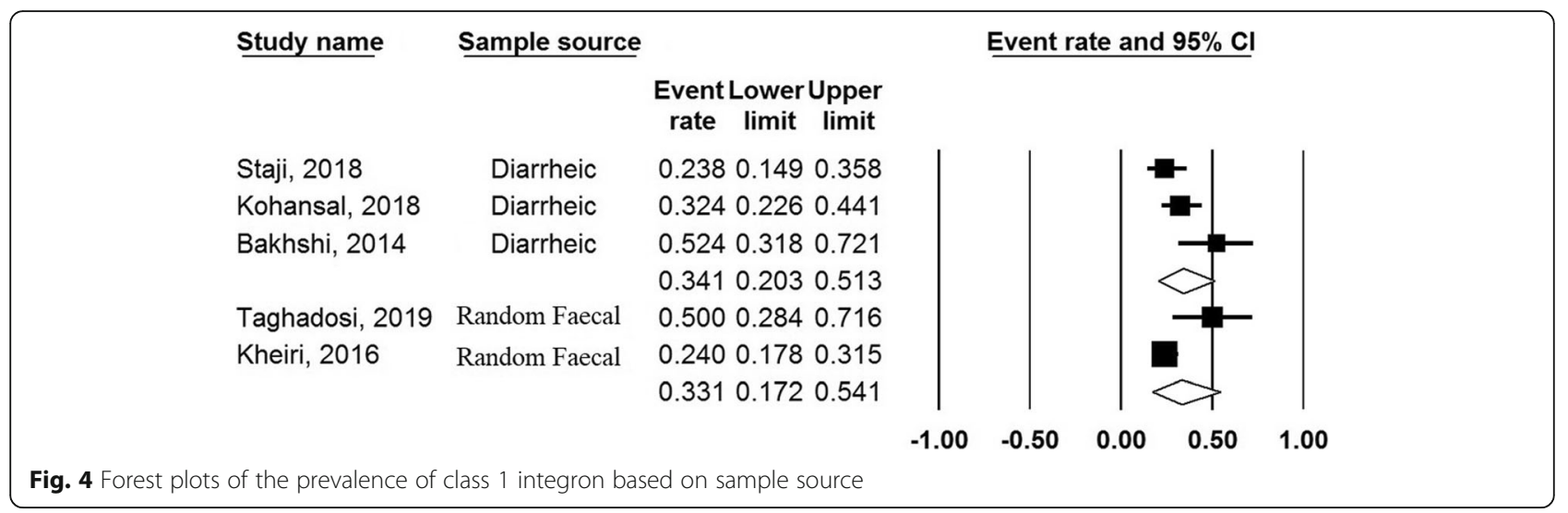

We collected detailed information by the researchers about the first author's name, the year of publication, the source of samples, the source of isolation, sample size, and the frequency of class 1 integron.

\section{Statistical analysis}

Analysis of data was done using the Comprehensive Meta-Analysis Software Version 2.2 (Biostat Company). The random-effects model was used to estimate the pooled prevalence and corresponding 95\% confidence interval (CI). Statistical heterogeneity between studies was estimated with the Cochran's Q statistic and I-square $\left(I^{2}\right)$ test. The funnel plot, Begg's rank correlation test, and Egger's weighted regression tests were used to evaluate the possibility of publication bias $(p<0.05$ was considered as indicative of statistically significant publication bias).

Possible sources of heterogeneity were calculated using sensitivity analysis and subgroup analysis based on the location of the study, and sample source was assessed to calculate possible sources of heterogeneity

\section{Results}

Database search and characterization of studies

The database search yielded 205 citations. Among them, 196 were removed by index, title, and abstract screening and 9 were retrieved in full text [16-24]. Of 9 reviewed studies, in a study, samples were collected from aquaculture water [16], and the results of three studies were unclear thus, four studies were excluded upon a full-text search [22-24]. Finally, based on inclusion criteria, 5 studies were included to meta-analysis [17-21]. The searching process for collection of qualified studies is shown in Fig. 1. The full results of the selected articles such as sample size, type of animal, the frequency of Int1, and source of samples are presented in Table 1. All studies examined the frequency of Int1 in cattle, goats, chicken, sheep, and calves. Also, all of isolates were recovered from faecal sample.

\section{Prevalence of class 1 integrons}

From included studies, the pooled prevalence of class 1 integron was 33\% (95\% CI, 23.8-43.7\%) ranging from 23.8 to $52.4 \%$ (Fig. 2). There was a significant heterogeneity among the 5 studies $\left(\chi^{2}=11.73 ; p<0.019 ; I^{2}=65.91 \%\right)$. Additionally, the funnel plot, Begg's, and Egger's tests were performed to quantitatively evaluate the publication biases. The funnel plot showed no evidence of asymmetry. According to the results of Begg's test $(z=1.22, p=0.22)$ and Egger's test $(t=3.03, p=0.056)$, a significant publication bias was not observed (Fig. 3).

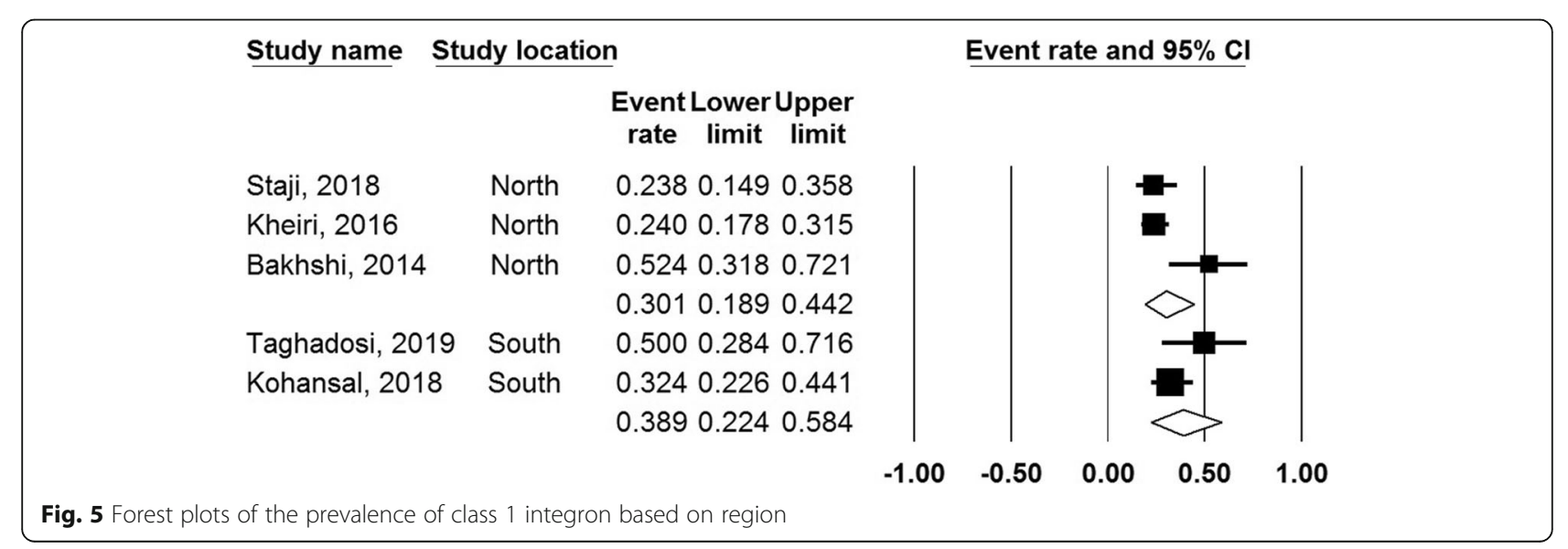




\section{Study name}

\section{Lower Upper Point limit limit $p$-Value}

\begin{tabular}{|c|c|c|c|}
\hline Taghadosi, 2019 & 0.3020 .217 & 0.404 & 0.000 \\
\hline Staji, 2018 & 0.3630 .243 & 0.502 & 0.054 \\
\hline Kohansal, 2018 & 0.3410 .217 & 0.491 & 0.038 \\
\hline Kheiri, 2016 & 0.3680 .250 & 0.504 & 0.057 \\
\hline Bakhshi, 2014 & 0.2930 .217 & 0.382 & 0.000 \\
\hline & 0.3300 .238 & 0.437 & 00 \\
\hline
\end{tabular}

\section{Event rate $(95 \% \mathrm{Cl})$ \\ with study removed}

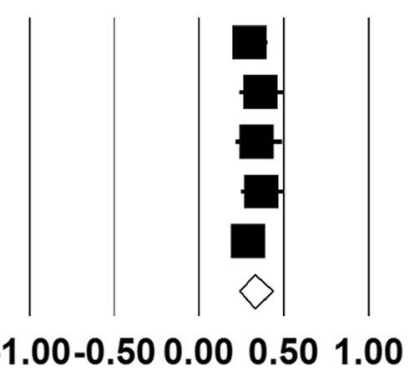

Fig. 6 Sensitivity plot of eligible studies included in the meta-analysis

\section{Subgroup analysis of prevalence of class 1 integrons} The finding of subgroup analysis based on sample source revealed that the prevalence of class 1 integrons among diarrheic and healthy samples were $34.1 \%$ (95\% CI, 20-51\%) and 33.1\% (95\% CI 17$54 \%)$, respectively. Moreover, subgroup analysis based on region showed that the prevalence of class 1 integrons were $30 \%$ and $39 \%$ in the North and South of the Iran, respectively (Figs. 4 and 5).

\section{Sensitivity analysis}

According to sensitivity analysis results, none of the eligible studies has the ability to change the overall prevalence substantially (Fig. 6).

\section{Discussion}

Nowadays, there are considerable data suggesting that excessive and improper administration of drugs to farm animals without being aware of the consequences of them leads to increasing the antibiotic-resistant bacteria, especially in humans [25-28]. Unfortunately, in Iran, similar to other countries, antibiotic precipitation in farm animals is relatively frequent and widespread $[29,30]$. Therefore, owing to the importance of drug resistance in animal farms and the possibility of their transmission into clinically important bacteria, the evaluation of drug resistance, especially the antibiotic resistance mechanisms, should be considered [31]. Integrons and other related gene cassettes are regarded as important genetic determinants of MDR strain in E. coli. These elements participate particularly in the horizontal transmission of genes involved in antibiotic resistance among clinical isolates of $E$. coli $[17,20]$.

To the best of our knowledge, this is the first comprehensive meta-analysis addressing the frequency of class 1 integrons in $E$. coli obtained from a different animal in Iran. Based on this meta-analysis, the frequency of class 1 integrons in E. coli recovered from domestic animal varied from 23.8 to $52.4 \%$. Furthermore, the pooled prevalence of class 1 integrons was calculated as $33 \%$. The prevalence of class 1 integrons in $E$. coli isolates has been variable in different reports ranging from $>50 \%$ in studies conducted in Chile (37.3\% in Poultry), Korea (31.7\% in poultry and Swine), China (41.94\% in chicken farm), China (36.8\% in bovine), and Norwegian origin (12\% in swine and poultry meat), being partially consistent with our findings [15, 32-35]. Compared to our study, $\mathrm{Su}$ et al. investigated the occurrence of integrons in Enterobacteriaceae isolated from integrated fish farms. The intI1 gene was found in $83.7 \%$ isolates of Enterobacteriaceae, which had a higher rate than ours [36].

The low frequency of class 1 integrons may be owing to presence of other resistance mechanisms such as intrinsic resistance factors, reduced permeability of the bacterial outer membrane, production of beta-lactamase enzymes, and overexpression of efflux pumps [37-39]. Furthermore, the discrepancy in the prevalence of class 1 integrons in different studies can partially be owing to geographical variation, type of studies animals, and improper and excessive use of antibiotic [17, 20]. In one study conducted by Zeeshan Khan et al., class 1 integrons in multidrug-resistant uropathogenic E. coli isolates were assessed. Based on their results, 79\% of MDR E. coli isolates harbored class 1 integrons [38]. Moreover, in Iran, in one study conducted by Pormohammad et al., the prevalence of integron classes in Gram-negative clinical isolates was reported. Based on this report, the prevalence of integron class 1 was $41 \%$, being inconsistent with the rate of integron class 1 in E. coli isolated from animal sources [40]. According to these literature reviews, the higher rate of integrons can lead to significant antibiotic resistance and consequently the emergence of ESBL and MDR isolates, which could be a serious risk to healthcare systems as well as livestock and poultry industries $[41,42]$. The frequency of class 1 integron in Iran is 
comparable to human resources. Although compared to human samples, the overall frequency of class 1 integron in animal resources was low, awareness about this information is vital owing to a higher occurrence of antibiotic resistance in these isolates [24, 41].

The role of class 1 integron in resistance to new generation antibiotics was characterized. Thus, based on the structure of class 1 integron gene cassettes, the presence of ESBLs and Metallo- $\beta$-lactamases (MBLs) hydrolyzing third and fourth generation cephalosporins and carbapenems leads to resistance to these classes of antibiotics $[43,44]$. Integrons, as mobile elements, can transmit and carrier the resistance genes from one organism to others; this challenge in livestock and poultry industries is extremely important, since the performance of infection control programs is poor [45-47]. According to our analysis, significant publication bias was not observed. However, it seems that various factors have stronger effects on the frequency of class 1 integron. Source of samples, geographical distribution, and sample size are among the factors in variation pathotypes of $E$. coli. Nevertheless, the analysis revealed that the weight of studies could not be reflected as an influence factor, and exclusion of any study has no remarkable effect on the estimated pooled prevalence. The main limitation of our study was heterogeneity among the included studies; thus, the results should be interpreted with caution.

\section{Conclusions}

Our findings demonstrated the relatively high prevalence of class 1 integrons among E. coli isolates. Furthermore, there was a significant heterogeneity among the studies. Moreover, subgroup analysis showed no difference in the prevalence of class 1 integrons among different sample sources.

\section{Supplementary information}

Supplementary information accompanies this paper at https://doi.org/10. 1186/s41182-020-00202-1.

Additional file 1. Study design according to the Preferred Reporting Items for Systematic Reviews and Meta-Analyses (PRISMA) guidelines.

\section{Abbreviations}

AMR: Antimicrobial resistance; Cl: Confidence interval; E. coli: Escherichia coli; GNB: Gram-Negative Bacteria; PRISMA: Preferred Reporting Items for Systematic Reviews and Meta-Analyses; MDR: Multidrug-resistant; MeSH: Medical subject headings

\section{Acknowledgements}

Not applicable.

\section{Authors' contributions}

MKD, MH, and SN designed and supervised, collected and analyzed the data, and drafted the manuscript. All authors read and approved the final manuscript.

\section{Funding}

Not funding
Availability of data and materials

The datasets used and/or analyzed during the current study are available from the corresponding author on reasonable request

Ethics approval and consent to participate

Not applicable.

Consent for publication

Not applicable.

\section{Competing interests}

The authors declare that they have no competing interests.

\section{Author details}

${ }^{1}$ Department of Clinical Sciences, Faculty of Veterinary Medicine, Shahrekord Branch, Islamic Azad University, Shahrekord, Iran. ${ }^{2}$ Department of

Microbiology, School of Medicine, Isfahan University of Medical Sciences, Isfahan, Iran. ${ }^{3}$ Department of Microbiology, Clinical Laboratory of Al Zahra Medical Centre, Isfahan University of Medical Sciences, Isfahan, Iran.

Received: 29 October 2019 Accepted: 11 March 2020

Published online: 07 April 2020

\section{References}

1. Chen M, Wu Y, Yu S, Liu S, Wang Y, Huang D, Xu X, Lin F. Drug resistance and integron genes in Escherichia coli isolated from urinary tract infection. J Nanosci Nanotechnol. 2019;19:5989-93.

2. Belanger L, Garenaux A, Harel J, Boulianne M, Nadeau E, Dozois CM. Escherichia coli from animal reservoirs as a potential source of human extraintestinal pathogenic E. coli. FEMS Immunol Med Microbiol. 2011;62:1-10.

3. Heredia N, García S. Animals as sources of food-borne pathogens: a review. Anim Nutr. 2018;4:250-5.

4. Delahoy MJ, Wodnik B, McAliley L, Penakalapati G, Swarthout J, Freeman MC, Levy K. Pathogens transmitted in animal feces in low- and middleincome countries. Int J Hyg Environ Health. 2018;221:661-76.

5. Hao H, Sander $P$, lqbal Z, Wang Y, Cheng G, Yuan Z. The risk of some veterinary antimicrobial agents on public health associated with antimicrobial resistance and their molecular basis. Front Microbiol. 2016;7:1626.

6. Salaheen S, Kim SW, Cao H, Wolfgang DR, Hovingh E, Karns JS, Haley BJ, Van Kessel JAS. Antimicrobial resistance among Escherichia coli isolated from veal calf operations in Pennsylvania. Foodborne Pathog Dis. 2019;16:74-80.

7. Aslam B, Wang W, Arshad MI, Khurshid M, Muzammil S, Rasool MH, Nisar MA, Alvi RF, Aslam MA, Qamar MU, et al. Antibiotic resistance: a rundown of a global crisis. Infect Drug Resist. 2018;11:1645-58.

8. Chamosa LS, Álvarez VE, Nardelli M, Quiroga MP, Cassini MH, Centrón D. Lateral Antimicrobial Resistance Genetic Transfer is active in the open environment. Sci Rep. 2017;7:513.

9. Leungtongkam U, Thummeepak R, Tasanapak K, Sitthisak S. Acquisition and transfer of antibiotic resistance genes in association with conjugative plasmid or class 1 integrons of Acinetobacter baumannii. PLoS One. 2018; 13:e0208468.

10. Domingues S, da Silva GJ, Nielsen KM. Integrons: vehicles and pathways for horizontal dissemination in bacteria. Mob Genet Elements. 2012;2:211-23.

11. Ghaly TM, Chow L, Asher AJ, Waldron LS, Gillings MR. Evolution of class 1 integrons: mobilization and dispersal via food-borne bacteria. PLoS One. 2017;12:e0179169.

12. Jones-Dias D, Manageiro V, Ferreira E, Barreiro P, Vieira L, Moura IB, Caniça M. Architecture of class 1, 2, and 3 integrons from Gram negative bacteria recovered among fruits and vegetables. Front Microbiol. 2016;7:1400.

13. Tsakris A, Poulou A, Kristo I, Pittaras T, Spanakis N, Pournaras S, Markou F. Large dissemination of VIM-2-metallo- $\beta$-lactamase-producing Pseudomonas aeruginosa strains causing health care-associated community-onset infections. J Clin Microbiol. 2009:47:3524-9.

14. Bonnet R. Growing group of extended-spectrum $\beta$-lactamases: the CTX-M enzymes. Antimicrob Agents Chemother. 2004;48:1-14.

15. Zhao H-X, Shen J-Z, An X-P, Fan H-L, Cao J-S, P-f L. Characterization of integrons in multiple antimicrobial resistant Escherichia coli isolates from bovine endometritis. Res Vet Sci. 2011;91:412-4.

16. Tajbakhsh E, Khamesipour F, Ranjbar R, Ugwu IC. Prevalence of class 1 and 2 integrons in multi-drug resistant Escherichia coli isolated from aquaculture 
water in Chaharmahal Va Bakhtiari province, Iran. Ann Clin Microbio Antimicrob. 2015;14:37

17. Taghadosi R, Shakibaie MR, Hosseini-Nave H. Antibiotic resistance, ESBL genes, integrons, phylogenetic groups and MLVA profiles of Escherichia coli pathotypes isolated from patients with diarrhea and farm animals in southeast of Iran. Comp Immunol Microbiol Infect Dis. 2019;63:117-26.

18. Staji H, Tonelli A, Zahraei TS, Mahdavi A, Shahroozian E, Salimi MB, Mehdizade SM, Keywanloo M, Ahmadi MH, Emadi HC. Distribution of antibiotic resistance genes among the phylogroups of Escherichia coli in diarrheic calves and chickens affected by colibacillosis in Tehran, Iran. Arch Razi Inst. 2018;73:131-7.

19. Kohansal M, Asad AG. Molecular analysis of Shiga toxin-producing Escherichia coli 0157: H7 and non-0157 strains isolated from calves. Onderstepoort J Vet Res. 2018;85:1-7.

20. Kheiri R, Ranjbar R, Khamesipour F, Akhtari L. Role of antibiotic in drug resistance and integrons prevalence in Escherichia coli isolated from human and animal specimens. Mol Microbiol. 2016;1:3.

21. Bakhshi B, Najibi S, Sepehri-Seresht S. Molecular characterization of enterohemorrhagic Escherichia coli isolates from cattle. J Vet Med Sci. 2014:76:1195-9.

22. Kheiri $R$, Akhtari $L$. Antimicrobial resistance and integron gene cassette arrays in commensal Escherichia coli from human and animal sources in IRI. Gut Pathog. 2016;8:40.

23. Doosti Irani M, Faghani M. Study of class 1 and 2 integrons and antimicrobial resistance in Salmonella isolated from broiler chicks in Chaharmahal va Bakhtiari province. Iran J Med Microbiol. 2016;10:38-44.

24. Firoozeh F, Zahraei-Salehi T, Shahcheraghi F. Molecular clonality and detection of class 1 integron in multidrug-resistant Salmonella enterica isolates from animal and human in Iran. Microb Drug Resist. 2014;20:517-24.

25. Hoelzer K, Wong N, Thomas J, Talkington K, Jungman E, Coukell A Antimicrobial drug use in food-producing animals and associated human health risks: what, and how strong, is the evidence? BMC Vet Res. 2017;13:211.

26. Magouras I, Carmo LP, Stärk KDC, Schüpbach-Regula G. Antimicrobial usage and -resistance in livestock: where should we focus? Front Vet Sci. 2017:4:148.

27. Economou V, Gousia P. Agriculture and food animals as a source of antimicrobial-resistant bacteria. Infect Drug Resist. 2015;8:49-61.

28. Türkyilmaz S, Eskiizmirliler S. Detection of slime factor production and antibiotic resistance in staphylococcus strains isolated from various animal clinical samples. Turkish J Vet Anim Sci. 2006:30:201-6.

29. Alizade $\mathrm{H}$. Escherichia coli in Iran: an overview of antibiotic resistance: a review article. Iran J Public Health. 2018:47:1-12.

30. Aalipour F, Mirlohi M, Jalali M. Determination of antibiotic consumption index for animal originated foods produced in animal husbandry in Iran, 2010. J Environ Health Sci Eng. 2014;12:42.

31. Azm S, Rmdo J, Ma C-S, Kholif AE, Salem MZM, Elghandour MMMY. Detection of sensitive and mutant ruminal bacteria isolates from sheep, cattle, and buffalo using 14 therapeutic antibiotics. Turkish J Vet Anim Sci. 2014:38:514-9.

32. Lapierre Acevedo L, Cornejo J, Borie Polanco C, Toro C, San MB. Genetic characterization of antibiotic resistance genes linked to class 1 and class 2 integrons in commensal strains of Escherichia coli isolated from poultry and swine; 2008.

33. Kang HY, Jeong YS, Oh JY, Tae SH, Choi CH, Moon DC, Lee WK, Lee YC, Seol SY, Cho DT. Characterization of antimicrobial resistance and class 1 integrons found in Escherichia coli isolates from humans and animals in Korea. J Antimicrob Chemother. 2005:55:639-44.

34. Lu L, Dai L, Wang Y, Wu C, Chen X, Li L, Qi Y, Xia L, Shen J. Characterization of antimicrobial resistance and integrons among Escherichia coli isolated from animal farms in Eastern China. Acta Tropica. 2010;113:20-5.

35. Sunde M. Prevalence and characterization of class 1 and class 2 integrons in Escherichia coli isolated from meat and meat products of Norwegian origin. J Antimicrob Chemother. 2005;56:1019-24.

36. Su H-C, Ying G-G, Tao R, Zhang R-Q, Fogarty LR, Kolpin DW. Occurrence of antibiotic resistance and characterization of resistance genes and integrons in Enterobacteriaceae isolated from integrated fish farms in south China. J Environ Monit. 2011;13:3229-36.

37. Halaji M, Rezaei A, Zalipoor M, Faghri J. Investigation of class I, II, and III integrons among Acinetobacter Baumannii isolates from hospitalized patients in Isfahan, Iran. Oman Med J. 2018;33:37.

38. Khan FZ, Nawaz T, Mirani ZA, Khan S, Raza Y, Kazmi SU. Study of class 1 integrons in multidrug-resistant uropathogenic Escherichia coli isolated from different hospitals in Karachi. Iran J Basic Med Sci. 2018;21:1079.
39. Munita JM, Arias CA. Mechanisms of antibiotic resistance. Microbiol Spectr. 2016;4.

40. Pormohammad A, Nasiri MJ, Azimi T. Prevalence of antibiotic resistance in Escherichia coli strains simultaneously isolated from humans, animals, food, and the environment: a systematic review and meta-analysis. Infect Drug Resist. 2019;12:1181-97.

41. Faghri J, Nouri S, Jalalifar S, Zalipoor M, Halaji M. Investigation of antimicrobial susceptibility, class I and II integrons among Pseudomonas aeruginosa isolates from hospitalized patients in Isfahan, Iran. BMC Res Notes. 2018;11:806.

42. Falgenhauer L, Imirzalioglu C, Oppong K, Akenten CW, Hogan B, Krumkamp R, Poppert S, Levermann V, Schwengers O, Sarpong N, et al. Detection and characterization of ESBL-producing Escherichia coli from humans and poultry in Ghana. Front Microbiol. 2018;9:3358.

43. Fluit A, Schmitz F. Class 1 integrons, gene cassettes, mobility, and epidemiology. Eur J Clin Microbiol Infect Dis. 1999:18:761-70.

44. Mazel D. Integrons: agents of bacterial evolution. Nat Rev Microbiol. 2006;4:608,

45. Fletcher S. Understanding the contribution of environmental factors in the spread of antimicrobial resistance. Environ Health Prev Med. 2015;20:243-52.

46. Seiffert SN, Hilty M, Perreten V, Endimiani A. Extended-spectrum cephalosporin-resistant Gram-negative organisms in livestock: an emerging problem for human health? Drug Resist Updat. 2013;16:22-45.

47. Marshall BM, Levy SB. Food animals and antimicrobials: impacts on human health. Clin Microbiol Rev. 2011;24:718-33.

\section{Publisher's Note}

Springer Nature remains neutral with regard to jurisdictional claims in published maps and institutional affiliations.
Ready to submit your research? Choose BMC and benefit from:

- fast, convenient online submission

- thorough peer review by experienced researchers in your field

- rapid publication on acceptance

- support for research data, including large and complex data types

- gold Open Access which fosters wider collaboration and increased citations

- maximum visibility for your research: over $100 \mathrm{M}$ website views per year

At BMC, research is always in progress.

Learn more biomedcentral.com/submissions 